Artigo original

Hegemonia - Revista Eletrônica de Relações Internacionais do Centro Universitário Unieuro

ISSN: $1809-1261$

UNIEURO, Brasília, número 17, 2016, pp. 227-236.

Recebido em: 24/8/2015

Avaliado em:17/9/2015

Aprovado em: 13/10/2015

\title{
A Primeira Guerra Mundial, 1914-1918: \\ Ensaio Bibliográfico
}

Carlos Federico Domínguez Avila ${ }^{1}$

Christopher CLARK. Os Sonâmbulos: Como Eclodiu a Primeira Guerra Mundial. Tradução de Berilo Vargas e Laura Teixeira Motta. São Paulo, Companhia das Letras, 2014. 700 páginas.

Lawrence SONDHAUS. A Primeira Guerra Mundial. História Completa. Tradução de Roberto Cataldo Costa. São Paulo, Contexto, 2014. 555 páginas.

Delmo de Oliveria ARGUELHES. Sob o Céu das Valquírias. As Concepções de heroísmo e honra dos pilotos de caça na Grande Guerra (1914-19). Curitiba, Editora CRV, 2013. 231 páginas.

Em 28 de junho de 1914, o bósnio-sérvio Gavrilo Princip disparou e acertou o príncipe-herdeiro do Império Austro-Húngaro e sua esposa, Francisco Ferdinando e Sophie Chotek, respectivamente. Trinta e sete dias depois do atentado em Sarajevo, o continente europeu iniciava a Grande Guerra (1914-1918). Essa conflagração provocou a morte de

Doutor em História das Relações Internacionais, docente do Centro Universitário Unieuro. 
Artigo original

Hegemonia - Revista Eletrônica de Relações Internacionais do Centro Universitário Unieuro

ISSN: $1809-1261$

UNIEURO, Brasília, número 17, 2016, pp. 227-236.

aproximadamente 20 milhões de pessoas, causou graves ferimentos a outros 21 milhões, e forçou uma significativa recomposição da ordem mundial, dentre outras trágicas e dramáticas conseqüências. Assim, no contexto das comemorações do centenário do início daquela conflagração européia e mundial têm sido lançadas numerosas obras sobre o assunto, dentre elas as três que são objeto da presente resenha.

A primeira obra, intitulada Os Sonâmbulos, é do australiano Christopher Clark. Publicado originalmente em 2012, e lançado no Brasil em maio de 2014 pela Companhia das Letras, a obra resenhada tem recebido críticas muito positivas de especialistas, acadêmicos e do grande público em numerosos países. Esses elogios são merecidos. O trabalho de Clark se fundamenta em uma sólida e formidável pesquisa em arquivos e literatura especializada - inclusive documentos diplomáticos procedentes de uma dezena de países europeus, de memórias, e de fontes hemerográficas.

Igualmente, é possível perceber significativas inovações metodológicas, particularmente no que diz respeito ao estudo dos processos de tomada de decisões em contexto de crise, ao denominado cálculo estratégico - isto é, a correlação entre objetivos, meios e riscos em política -, e ao análise de política externa. Nessa linha, a obra dialoga com os estudos históricos, com os estudos políticos, com as relações internacionais, com as ciências sociais, e com os estudos interdisciplinares.

A estrutura interna do livro inclui três partes. A primeira parte, intitulada Caminhos para Sarajevo (capítulos 1 e 2), explora as complexas relações bilaterais entre a Sérvia e a Áustria-Hungria, com destaque para a questão do irredentismo dos eslavos do sul - isto é, dos sérvios, dos bósnios e, em menor medida, dos croatas. A segunda parte, intitulada Um Continente Dividido (capítulos 3 a 6), aborda a dinâmica geopolítica européia, então caracterizada pela tensa co-existência de duas alianças antagônicas; de um lado, a denominada Tríplice Aliança (Alemanha, Áustria-Hungria e Itália), e 
Artigo original

Hegemonia - Revista Eletrônica de Relações Internacionais do Centro Universitário Unieuro

ISSN: $1809-1261$

UNIEURO, Brasília, número 17, 2016, pp. 227-236.

de outro, a Tríplice Entente (França, Rússia e Reino Unido). E a terceira parte, denominada Crise (capítulos 7 a 12), avalia os desdobramentos do atentado em Sarajevo até o início das hostilidades nos diferentes teatros de operações militares, especialmente no continente europeu, nas colônias das potências beligerantes e nos oceanos. Cumpre adiantar que essa última parte é, salvo melhor interpretação, a mais significativa, proveitosa e relevante do livro.

Com efeito, é pelo magistral estudo da crise de julho de 1914 que Clark continua recebendo os elogios da comunidade acadêmica e do público. Acontece que a crise de julho de 1914 se erigiu em um acontecimento e em problema-objeto de pesquisa extremamente complexo. Quando comparado à crise dos mísseis soviéticos em Cuba, de 1962, percebemos que a crise de julho de 1914 teve mais atores envolvidos - três atores fundamentais no primeiro caso (Estados Unidos, União Soviética e Cuba), e uma dezena de atores mais ou menos independentes e autônomos no segundo acontecimento citado (Sérvia, Áustria-Hungria, Rússia, Alemanha, França, Reino Unido, Bulgária, o Império Otomano e, em menor medida, Albânia, Grécia e Itália), sem esquecer algumas organizações secretas ligadas diretamente ao atentado em Sarajevo.

Ao longo da densa obra ora resenhada é possível verificar numerosos tópicos essenciais no estudo da crise: (i) o clima de desconfiança recíproca entre as alianças antagônicas, (ii) a temerária predisposição a correr riscos, seja para dissuadir os potenciais adversários ou para disciplinar e assegurar a lealdade dos aliados, (iii) a complexa correlação entre fatores estruturais e mudanças conjunturais ou de curto prazo, (iv) as ideologias nacionalistas e militaristas predominantes na época, ( $v$ ) os planos estratégicos e os desígnios dos Estados (ou sistema de finalidade), e (vi) o uso político do atentado de Sarajevo pelas grandes potências com intuito de alcançar outros objetivos almejados ao longo de muitos anos. Nessa linha, o autor do livro afirma categoricamente o seguinte: "Todos os autores principais de nossa história filtravam o mundo através de 
Artigo original

Hegemonia - Revista Eletrônica de Relações Internacionais do Centro Universitário Unieuro

ISSN: $1809-1261$

UNIEURO, Brasília, número 17, 2016, pp. 227-236.

narrativas construídas com pedaços de experiência coladas por medos, projeções e interesses disfarçados de máximas" (p. 584).

Paralelamente, Clark demonstra convincentemente que, em contraste com a imagem do ator racional unificado própria do pensamento realista clássico, todas as principais potências com vínculos e interesses na crise de julho de 1914 experimentavam significativas disputas inter-burocráticas, especialmente entre as elites civis, militares, e parlamentares. Algo semelhante se observou em relação aos atores não-estatais e do que na atualidade é chamado de agentes da sociedade civil. Inclusive no despótico Império Russo se verificaram divergências inter-burocráticas significativas, dado que - cenário balcânico ou especificamente servo-austríaco poderia desbordar gerando uma guerra européia, em conseqüência, o tsar Nicolau II postergou a mobilização geral das forças armadas do seu país por um dia para tentar encontrar, in extremis, uma saída político-diplomática junto com o seu primo o kaiser Guilherme II, e evitar a guerra - iniciativa que, finalmente, não prosperou. Nesse sentido, acertou o pesquisador australiano ao sublinhar o seguinte:

Os principais decisores - reis, imperadores, ministros das Relações Exteriores, embaixadores, comandantes militares e uma multidão de autoridades menores - caminharam em direção ao perigo em passos vigilantes, calculados. A eclosão da guerra foi a culminância de cadeias de decisões tomadas por agentes políticos com objetivos conscientes, que eram capazes de certo grau de autorreflexão, avaliaram um conjunto de opções e fizeram os melhores julgamentos ao seu alcance com base nas melhores informações de que dispunham. Nacionalismo, armamentos, alianças e finanças foram, todos, parte da história, mas só podemos dar-lhes um peso explicativo se for possível considerar que eles moldaram as decisões que - combinadas - fizeram a guerra eclodir [p. 28]. 
Artigo original

Hegemonia - Revista Eletrônica de Relações Internacionais do Centro Universitário Unieuro

ISSN: $1809-1261$

UNIEURO, Brasília, número 17, 2016, pp. 227-236.

A forte inclinação metodológica de Clark pela documentação político-diplomática e pelo estudo dos processos de tomada de decisões acaba valorando fundamentalmente os atos e o papel das elites e das lideranças, isto é, dos denominados homens de Estado. Segundo o autor do livro, essa opção atenderia ao objetivo de "reconstituir o mais vividamente possível as 'posições de decisão' altamente dinâmicas ocupadas pelos principais atores antes e durante o verão de 1914" (p. 29). Acreditamos que o pesquisador australiano consegue alcançar seu objetivo geral de forma muito satisfatória.

Ainda no campo metodológico, parece pertinente - e acertada a opção de Clark por responder prioritariamente a questão do Como se gestou e se desenvolveu a crise de julho de 1914, e somente de forma subsidiária e indireta assumir a ainda mais espinhosa questão do Porquê. Resumidamente o como pretende compreender as idéias, interpretações e preocupações dos diferentes atores em conflito de forma equilibrada e isenta. Nessa linha, todos os atores envolvidos tinham interesses objetivos, verificáveis e concretos a defender e sustentar. Em outras palavras, ninguém era totalmente virtuoso, inocente ou pacífico no conflito - "precisamos entender como esses acontecimentos foram vivenciados e entremeados em narrativas que estruturaram as percepções e motivaram os comportamentos", assinala o autor do livro. Paralelamente, o Clark recusa, ao máximo, esbarrar nos porquês, inclusive para evitar ser forçado a adotar visões teleológicas ou ex post facto que certamente resultariam, por exemplo, na questão da culpabilidade e em outros dilemas morais de difícil - ou impossível? - resolução sob uma perspectiva estritamente científica.

A esse respeito, parece pertinente lembrar que, segundo o tratado de Versalhes, de 1919, o tema da culpabilidade da guerra foi atribuído fundamentalmente à Alemanha. Contudo, uma avaliação mais isenta e bem documentada não pode deixar de constatar que o sistema de alianças antagônicas, a qualidade das lideranças, os 
Artigo original

Hegemonia - Revista Eletrônica de Relações Internacionais do Centro Universitário Unieuro

ISSN: $1809-1261$

UNIEURO, Brasília, número 17, 2016, pp. 227-236.

interesses e ambições imperialistas das classes dominantes especialmente dos lobbies industriais e financeiros -, e até a cultura política de orientação militarista predominante em numerosas sociedade européias tiveram igual ou maior responsabilidade do que a política germânica diante dos disparos de Sarajevo, em particular, e da geopolítica continental e global, em geral. Nesse sentido, cobra relevância, significado e pertinência o próprio título da obra: "os protagonistas de 1914 eram sonâmbulos, despertos mais incapazes de enxergar, atormentados por sonhos, mas cegos para a realidade do horror que logo mais trariam para o mundo" (p. 589).

A segunda obra resenhada, intitulada A Primeira Guerra Mundial: História Completa, é do historiador estadunidense Lawrence Sondhaus, foi publicada pela Editora Contexto, e constitui uma virtual continuação do trabalho de pesquisa que se desenvolve desde Sarajevo até a assinatura do Tratado de Versalhes (1919). Com efeito, trata-se de um livro que oferece um panorama bastante completo, equilibrado e profissional da evolução do conflito, do encerramento das hostilidades e das primeiras repercussões da conflagração. Essa obra foi publicada originariamente nos Estados Unidos, em 2011.

Ao longo de quinze capítulos, Sondhaus explora as vicissitudes, os horrores e as perspectivas dos principais atores envolvidos no conflito. O autor discute, com muita propriedade, todos os principais teatros de operações militares e batalhas. Eis os casos dos frentes Ocidental, Oriental, Balcânico, Arábigo, e colonial; sem esquecer as correspondentes operações navais e aéreas. Essa narrativa é enriquecida com pertinentes mapas, retratos fotográficos e excertos de documentos originais e entrevistas de lideranças políticas, militares e societais. No campo doméstico, também destaca-se o estudo dos diferentes atores sociopolíticos, das classes subalternas, das classes médias, das elites, dos povos colonizados, dentre outros. 
Artigo original

Hegemonia - Revista Eletrônica de Relações Internacionais do Centro Universitário Unieuro

ISSN: $1809-1261$

UNIEURO, Brasília, número 17, 2016, pp. 227-236.

Sondhaus também demonstra grande familiaridade com as inovações da tecnologia militar e da estratégia utilizadas na condução da guerra pelos beligerantes. Particular interesse apresenta o uso de armas químicas, dos blindados, da aviação militar, da industria da defesa. O rigor do alistamento militar, as conseqüências humanas da guerra, as revoluções sociais triunfantes na Rússia, Áustria-Hungria e no Império Otomano, e o impacto da entrada dos Estados Unidos no conflito (em 1917) são lembradas persistentemente pelo autor do livro.

A terceira obra resenhada, intitulada Sob o Céu das Valquírias, é uma contribuição do historiador brasileiro Delmo Arguelhes, lançada pela Editora CRV. Trata-se de uma versão ajustada da sua Tese de Doutoramento em História das Idéias, apresentada na Universidade de Brasília, em 2008. O livro, organizado em cinco capítulos, é sumamente relevante, interessante e significativo. Sendo que, no campo metodológico, o autor tira proveito dos modernos paradigmas nas ciências históricas, especialmente no estudo das mentalidades, dos conceitos e das ideologias.

O problema-objeto do livro é explorar a recomposição da imagem dos pilotos de caça da Primeira Guerra Mundial sob a perspectiva da noção dos cavalheiros medievais. Nessa linha, o autor demonstra que muitos pilotos de caça passaram a ser vistos pelas sociedades como modernos cavalheiros, inclusive no que diz respeito ao uso, mais ou menos difundido, das noções de heroísmo, honra, estirpe, espírito de corpo e transcendência.

Arguelhes fundamenta sua pesquisa em memórias dos pilotos de caça, nos relatos mitológicos e em literatura especializada publicada fundamentalmente no continente europeu. Cumpre mencionar que as memórias dos pilotos de caça não são neutras, sendo que alguns desses livros foram publicados ainda durante 0 conflito. Mesmo assim, o interessante é verificar que os pilotos de caça das diferentes nacionalidades compartilhavam de um espírito de 
Artigo original

Hegemonia - Revista Eletrônica de Relações Internacionais do Centro Universitário Unieuro

ISSN: $1809-1261$

UNIEURO, Brasília, número 17, 2016, pp. 227-236.

corpo e até um certo senso de empáfia conjunta com relação ao restante das forças armadas. Só assim se entende que, apos de ser abatido e capturado pelos adversários, os pilotos franceses eram agraciados com uma recepção pelos equivalentes alemães, e posteriormente enviados aos campos de prisioneiros.

O tema em questão é denso e complexo. Mesmo assim, o autor demonstra um excepcional domínio do problema-objeto. E o resultado final é muito positivo e construtivo. Nesse sentido, Arguelhes demonstra que os historiadores brasileiros e latinoamericanos também podem realizar contribuições de alta qualidade ao debate sobre história global, história contemporânea e história social.

Em síntese, as três obras resenhadas são contribuições valiosas para historiadores, estudantes e opinião pública, em geral. Certamente a Primeira Guerra Mundial impulsionou mudanças revolucionárias na Europa e no mundo. Os livros são resultado de pesquisa profissional. Ao longo dos diferentes capítulos logramos aprimorar os nossos conhecimentos sobre a origem, a evolução, o encerramento das hostilidades e as conseqüências após quatro anos de guerra. Os autores abordam o esquema das alianças antagônicas, e os teatros de operações militares (terrestres, navais, aéreas e domésticas). Também, exploram-se o cálculo estratégico dos governantes, a tecnologia militar, a recomposição nas relações de classe, gênero e dominação centro-periferia, e as mentalidades coletivas.

Vale acrescentar que o trabalho de tradução para o português das duas primeiras obras é muito bom - ainda que seja possível constatar algumas poucas imprecisões de datas e locais. As três editoras envolvidas - Companhia das Letras, Contexto e CRV, respectivamente - estão de parabéns e podem sentir-se orgulhosas pela acertada determinação de colocar as mencionadas obras à disposição do público brasileiro, em particular, e lusófono, em geral. 
Artigo original

Hegemonia - Revista Eletrônica de Relações Internacionais do Centro Universitário Unieuro

ISSN: $1809-1261$

UNIEURO, Brasília, número 17, 2016, pp. 227-236.

Entende-se que o contexto da comemoração do centenário do inicio da Primeira Guerra Mundial é um excelente motivo para realizar o esforço de publicação no Brasil de um conjunto de obras magistrais, da maior relevância científica, e de grande impacto acadêmico e social.

Finalmente, parece pertinente acrescentar que, no momento de escrever a presente resenha, existem numerosas crises políticas, econômicas, ambientais e étnicas no mundo que poderiam sair do controle dos governantes e das lideranças das principais potências mundiais, e acabar provocando um novo desastre humanitário. Eis os casos da virtual desintegração do Iraque, da emergência de diferentes tipos de fundamentalismos, do colapso da denominada Primavera Árabe (guerra na Síria, golpe no Egito, caos na Líbia e no Iraque), e a nova escalada no intratável conflito entre Israel e os palestinos (invasão da faixa de Gaza). Fora do Oriente Médio, é possível verificar graves conflitos na Ucrânia (inclusive com a derrubada de um avião comercial da Malásia, em julho de 2014, provocando a morte de quase 300 passageiros), numerosas divergências limítrofes terrestres e marítimas no Leste da Ásia, e a persistência de dificuldades econômico-financeiras na União Européia e em outros países capitalistas centrais.

O cenário internacional em 2014-15 é bem diferente do predominante em 1914. Entretanto, existem algumas preocupantes semelhanças, dentre outras a falta de lideranças carismáticas, combinada com a presença de certas chefias que parecem caminhar para a guerra como 'sonâmbulos'. O risco de uma crise internacional sem controle exige um permanente acompanhamento da sociedade civil e das organizações internacionais. Trata-se de evitar um novo desastre global, seja ele de natureza política, ambiental ou econômica. 